\title{
HYPERPYREXIA DURING ANAESTHESIA IN A SECOND MEMBER OF A FAMILY, WITH ASSOCIATED COAGULATION DEFECT DUE TO INCREASED INTRAVASCULAR COAGULATION
}

\author{
I. E. PURKIS, M.B., B.S., F.F.A.R.c.S., O. HORRELT, M.D., C. G. DE YOUNG, M.D., \\ R. A. P. Fleming, M.D., AND G. R. LANGLey, M.D., F.R.C.P.(C)
}

HYPERPYREXIA following anaesthesia, and associated with an abnormal reaction to succinylcholine (Anectine ${ }^{\oplus}$ ) though rare, has been the subject of a number of reports recently. ${ }^{1-4}$ The following case is reported to alert anaesthetists to a possible familial tendency to hyperthermia, and the simultaneous occurrence of an alteration in the coagulating mechanisms of the blood.

A married woman of French-Canadian descent, aged 44, was anaesthetized on December 14, 1966, for excision biopsy of a mass in the left breast, followed by radical mastectomy. Preoperatively, her history, physical examination and laboratory tests (see Table I) indicated normal health. Prior to the induction of anaes-

TABLE I

Electrolyte Changes in a Case of Hyperthermia

\begin{tabular}{|c|c|c|c|c|c|c|c|c|}
\hline & Dec. 13 & $\begin{array}{c}\text { Dec. } 14 \\
\text { 10:00 } \\
\text { A.M. }\end{array}$ & $\begin{array}{c}\text { 12:30 } \\
\text { P.M. }\end{array}$ & $\begin{array}{l}\text { 6:00 } \\
\text { P.M. }\end{array}$ & $\begin{array}{l}\text { 8:30 } \\
\text { P.M. }\end{array}$ & $\begin{array}{c}\text { Dec. } 15 \\
4: 00 \\
\text { A.M. }\end{array}$ & $\begin{array}{l}\text { 9:15 } \\
\text { A.M. }\end{array}$ & $12 \mathrm{~m}$. \\
\hline Temperature $\left({ }^{\circ} \mathrm{F}.\right)$ & 98 & 107 & 101 & 86 & 87 & 97.4 & 99 & $\begin{array}{c}\text { (post } \\
\text { mortem) }\end{array}$ \\
\hline $\begin{array}{l}\text { Blood urea (N) } \\
\text { Sodium (mEq./L.) } \\
\text { Potassium (mEq./L.) } \\
\text { Chloride (mEq./L.) } \\
\text { Calcium (mEq./I.). }\end{array}$ & 12 & $\begin{array}{l}138 \\
7.3 \\
96 \\
9.8\end{array}$ & $\begin{array}{c}150 \\
4.1 \\
82 \\
8.0\end{array}$ & $\begin{array}{c}135 \\
1.8 \\
84 \\
-\end{array}$ & $\begin{array}{l}138 \\
1.3 \\
88 \\
10.7\end{array}$ & $\begin{array}{c}148 \\
2.6 \\
94 \\
-\end{array}$ & $\begin{array}{c}148 \\
7.8 \\
94 \\
8.6\end{array}$ & $\begin{array}{c}160 \\
8.0 \\
70 \\
-\end{array}$ \\
\hline
\end{tabular}

thesia at 8:00 A.M. she was moderately sedated from meperidine (Demerol ${ }^{8}$ ) $75 \mathrm{mg}$. and atropine $0.4 \mathrm{mg}$. given one hour previously. Her temperature at 6:00 A.M. had been $98^{\circ} \mathrm{F}$., the blood pressure was $135 / 80 \mathrm{~mm}$. $\mathrm{Hg}$, and the pulse rate 70 per minute.

Anaesthesia was induced with $400 \mathrm{mg}$. of thiopentone, followed by $60 \mathrm{mg}$. of succinylcholine. Instead of normal fasciculations, this produced generalized hypertonus and jaw stiffness, with a decreased period of apnoea. Endotracheal intubation was accomplished with moderate difficulty, and was followed by a short period of coughing. The chest inflated easily, however, and there was no cyanosis. Induction of inhalation anaesthesia began with nitrous oxide $4 \mathrm{~L}$. and oxygen 3 L./min. and 1.5 per cent halothane through a semi-closed circuit. Respirations returned rapidly, and within three to five minutes became rapid (60 per min.) and deep, while the blood pressure rose to $170 / 80 \mathrm{~mm}$. Hg. On starting surgery, the surgeon remarked on the dark colour of the blood in the wound, but a careful check showed no misplacement of the endotracheal tube or interference with ventilation, and the patients lips and extremities seemed to have good colour.

-From the Departments of Anaesthesia and Medicine, Dalhousie University and Victoria General Hospital, Halifax, Nova Scotia. 
After ten minutes the blood pressure fell to $140 \mathrm{~mm}$. Hg systolic, though respirations remained rapid and deep at 40 per minute, the blood remained dark, and there was remarkably little bleeding during the biopsy. Frozen section indicated the tumour was malignant, and the surgeon proceeded with the radical mastectomy. A blood transfusion was begun slowly at 9:00 A.M. and speeded up when the patient's blood pressure suddenly fell at 9:30 A.M. to $65 \mathrm{~mm}$. Hg systolic and the pulse rate rose from 75 to 110 per min. Just prior to skin closure methoxamine (Vasoxyl\$) $2 \mathrm{mg}$. was given, and repeated without effect, and at this time the patient's skin was noted to be very warm.

A rectal thermometer was inserted and the patient's temperature was found to be $108^{\circ} \mathrm{F}$. Oxygen was substituted for anaesthesia, and rapid skin closure carried out. With the lightening anaesthesia, there were slight movements in response to surgical stimulus, and a gradual onset of generalized hypertonus, with severe carpopedal spasm, but without active shivering. Chlorpromazine (Largactil ${ }^{\circ}$ ) $50 \mathrm{mg}$. was given intravenously with no effect on the spasm, and diazepam (Valium) $10 \mathrm{mg}$. intravenously was also ineffective. D-tubocurarine (Tubarine $\left.{ }^{(}\right) 30 \mathrm{mg}$. produced some reduction in muscle tone, which was reinforced by a further $30 \mathrm{mg}$. A sodium bicarbonate infusion ( $595 \mathrm{mEq}$. in $500 \mathrm{ml}$.) was set up, and four $50 \mathrm{ml}$. vials of sodium bicarbonate (178.4 mEq.) were injected directly intravenously. Alcohol sponging was started while crushed ice and cooling blankets were being obtained. The patient was now atonic, except for slight carpopedal spasm, with a blood pressure of $30 \mathrm{~mm}$. Hg systolic, a pulse rate of 180 beats per minute, and an oesophageal temperature of $107^{\circ} \mathrm{F}$. as measured by thermistor probe. A central venous pressure cannula placed in the left internal jugular vein indicated a venous pressure of $5 \mathrm{~cm} . \mathrm{H}_{2} \mathrm{O}$, and blood was withdrawn from electrolyte determinations through this cannula. Blood for $\mathrm{pH}, \mathrm{P}_{\mathrm{CO}_{2}}$, and base determinations was withdrawn in a heparinized syringe from the left femoral artery.

Intravenous calcium gluconate in 10 per cent solution was given directly in 20 $\mathrm{ml}$. (2.0 gm.) doses to a total of $6.0 \mathrm{gm}$. Each dose improved the blood pressure and reduced the pulse rate, encouraging further doses, until the systolic pressure reached $110 \mathrm{~mm}$. $\mathrm{Hg}$ and the pulse rate fell to 120 , but no effect was noted on the remaining carpopedal spasm. At 10:00 A.M. the patient was placed on cooling blankets and surrounded by crushed ice, while being hyperventilated with oxygen through fresh soda lime. At 10:15 A.M. the laboratory reported that the first arterial specimen had clotted, but that $\mathrm{pH}$ was approximately 7.45 , and $\mathrm{P}_{\mathrm{CO}_{2}}$ in excess of 50 (Table II). A second arterial specimen was taken using $2.5 \mathrm{mg}$. $(1 / \mathrm{ml}$.) heparin in a 2 c.c. syringe, and this specimen also clotted soon after determination of a $\mathrm{pH}$ of 7.32, a $\mathrm{P}_{\mathrm{CO}_{2}}$ of 64.0 , and a standard bicarbonate of 26.4. Serum potassium was elevated to $7.3 \mathrm{mEq}$./L., with sodium, calcium, and chloride levels within normal limits.

By this time contact had been made with the patient's husband and it was learned that a niece of the patient ${ }^{*}$ had died four months previously from a

'This patient, a 14-year-old girl who was induced with thiopentone and given anectine for intubation, also failed to relax normally, and was intubated with difficulty. After a short operative procedure, sudden deterioration was noted in the recovery room, and the patient was found to be hyperthermic. While cooling was being instituted, cardiac arrest occurred from which the patient could not be resuscitated. 
TABLE II

alterations in Blood Gas and Acto-base Studies in a Case of Hyperthermia

\begin{tabular}{|c|c|c|c|c|c|}
\hline & $\begin{array}{l}\text { December } \\
\text { 10:00 A.M. }\end{array}$ & $\begin{array}{l}14 \\
10: 30 \text { A.M. }\end{array}$ & 12:15 P.M. & 7:00 P.M. & $\begin{array}{c}\text { December } 15 \\
\text { 4:00 A.M. }\end{array}$ \\
\hline $\begin{array}{l}\left.\text { Temperature ( }{ }^{\circ} \mathrm{F} .\right) \\
\mathrm{pH} \\
\mathrm{P}_{\mathrm{co}} \text { (mm. } \mathrm{Hg} \text { ) } \\
\text { Buffer base (mEq./L.) } \\
\text { Base excess (mEq./L.) } \\
\text { Standard bicarbonate (mEq./L.) } \\
\text { Actual bicarbonate (mEq./L.) } \\
\text { Total } \mathrm{CO}_{2} \text { (mEq./L.) }\end{array}$ & $\begin{array}{c}107 \\
7.449 \\
>50 \\
= \\
= \\
=\end{array}$ & $\begin{array}{l}107 \\
7.320 \\
64 \\
53.2 \\
+3.1 \\
26.4 \\
31.6 \\
33.5\end{array}$ & $\begin{array}{l}102 \\
7.389 \\
60.2 \\
56.7 \\
+8.3 \\
30.0 \\
35.0 \\
36.8\end{array}$ & $\begin{array}{l}86 \\
7.372 \\
42 \\
-0.6 \\
23.4 \\
=\end{array}$ & $\begin{array}{l}97.4 \\
7.415 \\
48 \\
+5.2 \\
28.4 \\
=\end{array}$ \\
\hline
\end{tabular}

hyperthermic reaction following anaesthesia for elective tonsillectomy in another Halifax hospital. ${ }^{5}$ By 10:30 A.M., the patient's temperature remained unchanged and arrangements for intravascular cooling were set in motion. For this reason, and because of the incre:sed clotting tendency, the patient was heparinized with a single $100 \mathrm{mg}$. dose of heparin intravenously. However, at 11:00 A.M., before intravascular cooling was available, the patient's temperature began to fall to $106^{\circ} \mathrm{F}$., and surface cooling only was continued. A Foley catheter was inserted into the bladder and 20-30 c.c. of clear red urine was obtained and sent for examination. This specimen was reported as strongly positive for haemoglobin, with few red cells, suggesting intravascular haemolysis. As the patient's temperature fell, the blood pressure declined too, and on transfer to intensive care at 12:45 P.M. her temperature was $99^{\circ} \mathrm{F}$., the systolic blood pressure $45 \mathrm{~mm}$. $\mathrm{Hg}$, and pulse rate 100 beats per minute. She was apnoeic, atonic, with the pupils moderately dilated and reacting sluggishly to light. The mastectomy wound had begun to ooze, with swelling and bruising extending into the left arm and neck. A "Haemovac" suction drainage trap had been inserted into the mastectomy wound, and the blood loss from this area could therefore be measured at frequent intervals. The electrocardiogram projected on an oscilloscope connected at this time showed widened QRS complexes and flattened $T$ waves, and the central venous pressure was $5.5 \mathrm{~cm} . \mathrm{H}_{2} \mathrm{O}$. Two units of blood had been given, and more was being cross-matched. Methoxamine (Vasoxyl $\left.{ }^{\oplus}\right) 40 \mathrm{~m}$. and hydrocortisone $100 \mathrm{mg}$. were added to the dextrose water and normal saline infusions, but by 1:30 P.M. the blood pressure had fallen to $35 \mathrm{~mm}$. $\mathrm{Hg}$ and the venous pressure to $3.5 \mathrm{~cm}$. $\mathrm{H}_{2} \mathrm{O}$, and low-molecular-weight dextran (Rheomacrodex 300 c.c. was given until blood was available at 2:00 P.M. Rapid transfusion gradually raised the venous pressure, but active bleeding increased, and the blood pressure remained unchanged. Protamine $30 \mathrm{mg}$. was given without effect to reverse the remaining heparin, and calcium gluconate was given at the rate of $1.0 \mathrm{gm}$. for each four bottles of blood. With rapid transfusion of cold blood the patient's temperature continued to drift downward to $90^{\circ} \mathrm{F}$. and active rewarming was begun. At 2:15 P.M. a blood specimen showed a prothrombin activity of 10 per cent of control, and a further examination of this specimen was reported at 3:30 as showing between 5 and 35 per cent activity of factors II, V, VII, X, and XI, with a euglobulin lysis time of $\mathbf{9 0}$ minutes compared to a control greater than two hours and prolonged partial thromboplastin time (Table III). The reduction 
TABLE III

Coagutation Studies in a Case with Hyperthermia*

\begin{tabular}{lcc}
\hline & Patient & Normal \\
\hline Whole blood clotting time & & \\
$\quad$ Lee White (minutes) & 44 & $5-15$ \\
Prothrombin activity (\%) & & \\
2:15 P.M. Dec. 14 & $<10$ & 100 \\
9:30 A.M. Dec. 15 & 42.5 & 100 \\
Partial thromboplastin time (sec.) & $>120$ & $30-40$ \\
Whole blood clot lysis (at 24 hours) & partial lysis & none \\
Euglobulin lysis time (min.) & 90 & $>120$ \\
Fibrinogen (Mg. \%) & 115 & $190-330$ \\
Factor II activity (\%) & 35 & $65-150$ \\
Factor V activity (\%) & 15 & $65-170$ \\
Factor X activity (\%) & 30 & $55-150$ \\
Factor VII + activity (\%) & 30 & $80-150$ \\
Factor XI (\%) & approximately 5 & $55-160$ \\
\hline *Except as noted all tests were on specimen obtained at 3:30 P.M., \\
December 14.
\end{tabular}

in the blood clotting factors was felt to be due to disseminated intravascular coagulation (consumption coagulopathy) which may have begun six or seven hours previously. After 1200 c.c. of fresh frozen plasma and $2.4 \mathrm{gm}$. of fibrinogen had been given with little effect on bleeding, heparin was given in an attempt to halt further intravascular consumption of clotting factors while blood loss was carefully monitored.

After $10 \mathrm{mg}$. of heparin, the blood loss fell from approximately $25 \mathrm{c.c} . / \mathrm{min}$. to $8 \mathrm{c.c} . / \mathrm{min}$. but then rose to its previous level in 30 minutes. A second injection of $20 \mathrm{mg}$. of heparin reduced blood loss from $25 \mathrm{c.c} . / \mathrm{min}$. to about $13 \mathrm{c.c} . / \mathrm{min}$. for 30 minutes, but again the loss returned to pretreatment levels. A subsequent $30 \mathrm{mg}$. of heparin had no effect, the blood loss actually increasing to $40 \mathrm{c.c} . / \mathrm{min}$. A further $2.8 \mathrm{gm}$. of fibrinogen and 1500 c.c. of fresh frozen plasma were then given to supply clotting factors, and blood to a total of 4,000 c.c. was given to match blood loss.

At 8:00 P.M., the patient was areflexic, atonic, and maintained on a respirator with controlled ventilation. Her rectal temperature was $87^{\circ} \mathrm{F}$., her systolic blood pressure $80 \mathrm{~mm}$. $\mathrm{Hg}$, the C.V.P. $6.0 \mathrm{~cm} . \mathrm{H}_{2} \mathrm{O}$, and the pulse rate 100 beats per minute. Mannitol (Osmitrol ${ }^{B}$ ) had been given at 3:00 P.M. because of complete anuria and a generalized oedema, and had resulted in a diuresis of an average of 285 c.c. of urine per hour ( 1170 c.c. over five hours) and reduction in oedema. Serum potassium (see Table I) had fallen from a high of $7.3 \mathrm{mEq} . / \mathrm{L}$. in the operating room, through a normal of $4.1 \mathrm{mEq}$. $/ \mathrm{L}$. on admission to intensive care, to a low of $1.3 \mathrm{mEq}$. $/ \mathrm{L}$. at this time, and $4 \mathrm{mEq}$. of potassium given as chloride were injected directly intravenously, while $36 \mathrm{mEq}$. were placed in the i.v. bottle. Following this, the E.K.G. showed narrowing of the QRS complex and increase of the $T$ wave towards a more normal height.

The patient continued to ooze blood and at 10:00 P.M. a further unit of blood was given, and $5 \mathrm{gm}$. of epsilon-amino caproic acid was given intravenously over one hour, then maintained at approximately $1 \mathrm{gm} . / \mathrm{hr}$. to control clot formation. 
By 12:00 P.M. there had been no effect on blood loss. Preparations were undertaken to reopen the mastectomy wound, tie off all active bleeding points and to coagulate oozing areas with cautery. Since the patient was hypothermic and atonic, no anaesthesia was required for this procedure, which was completed at 2:30 A.M. after the transfusion of a further 1500 c.c. of blood and 600 c.c. of plasma. The blood pressure was $95 / 60 \mathrm{~mm}$. $\mathrm{Hg}$, the C.V.P. $8.5 \mathrm{~cm} . \mathrm{H}_{2} \mathrm{O}$, and the pulse rate 120 per minute, but within half an hour the blood pressure had fallen to $70 / 55 \mathrm{~mm}$. Hg and the surgeon in charge ordered $2000 \mathrm{mg}$. of hydrocortisone to be given intravenously. This dose had no apparent effect.

During the remainder of the night, with the cessation of rapid transfusion, and with active rewarming, the patient's temperature began to rise slowly towards normal. By 7:00 A.M. on December 15, 23 hours after induction of anaesthesia, the rectal temperature was 99.4 , the blood pressure was stable at $70 / 55 \mathrm{~mm}$. $\mathrm{Hg}$. Only 60 c.c. of blood was lost from 2:30 A.M. to 7:00 A.M. The pulse rate had risen to 150 , and the patient showed signs of wakening, swallowing and opening her eyes on command. The pupils were small and equal, and reacted briskly to light, but general hypotonia remained, and all reflexes were depressed. An adequate urine output had been maintained through the night. The serum potassium had risen to $2.6 \mathrm{mEq}$./L. at 4:00 A.M. following infusion of the $40 \mathrm{mEq}$. of potassium chloride, and it was felt that all these signs of stabilization were encouraging.

At 8:00 A.M. the venous pressure cannula was responding sluggishly, so a fresh cannula was inserted on the opposite side, revealing a true venous pressure of $6 \mathrm{~cm} . \mathrm{H}_{2} \mathrm{O}$. Although the pulse rate had fallen to 110, a further unit of blood was given, and over the next hour the temperature, which had reached a peak of $101^{\circ} \mathrm{F}$., fell again to $99^{\circ} \mathrm{F}$. At this time the E.K.G. showed the widened QRS complexes and flattened $T$ waves that had previously been present with a low serum potassium, and at 9:00 A.M. $30 \mathrm{mEq}$. of potassium as $\mathrm{KCl}$ was added to the intravenous infusion. At $9: 30$, when approximately $15 \mathrm{mEq}$. had been given, the E.K.G. after gradual improvement, suddenly showed marked spiking of the $T$ waves, so the potassium infusion was stopped. One gramme of calcium gluconate was given to counteract the citrate in the last four transfusions. In spite of this, the $T$ wave continued to increase in height, and the pulse rate rose to 130 . At 9:50 A.M. severe carpopedal spasm returned, and was not relieved by d-tubocurarine $26 \mathrm{mg}$, or chlorpromazine $12.5 \mathrm{mg}$. Hydrocortisone $500 \mathrm{mg}$. was also given at this time with no apparent effect. While further supplies of d-tubocurarine were being obtained, cardiac arrest in asystole occurred, and all attempts at resuscitation were ineffective. It was later learned that a blood specimen taken at 9:15 A.M. showed a serum potassium of $7.8 \mathrm{mEq} . / \mathrm{L}$. and had clotted rapidly; a post mortem sample rechecked at $8.0 \mathrm{mEq} . / \mathrm{L}$.

At post mortem examination there was congestion and oedema of both lungs, and a recent left subdural haematoma (approximately 50 c.c.), probably terminal. There were no other gross anatomical abnormalities to account for the symptoms of the patient.

In view of a possible familial tendency to hyperthermia, efforts were made to identify relatives who might be affected, first to circulate a warning letter to be given to the anaesthetist in the event of a general anaesthetic being required, 
and secondly to identify the agents used in any previous anaesthetics given to the patient or her relatives. The patient has one living son aged 25 , a normal delivery, but had also had a Cesarean section resulting in a stillbirth 20 years ago. This was almost certainly under spinal anaesthesia. Although both parents are dead, neither died under anaesthesia. One sister, the mother of five children, one of whom was the child who died in hyperthermia following anaesthesia, was herself anaesthetized two years ago at the Victoria General Hospital for a cystoscopy as an outpatient. The anaesthesia consisted of a thiopentone induction (325 mg.) with maintenance of nitrous oxide, oxygen, and halothane. No relaxant was given, and the anaesthetic was without sequelae.

Her other sister, the mother of eight children, all living, was anaesthetized four years ago at the Victoria General Hospital for a vaginal hysterectomy. She was similarly induced with thiopentone (250 mg.) and maintained on nitrous oxide, oxygen, and halothane. Although she was not intubated, succinylcholine and decamethonium (Syncurine $1 \mathrm{mg}$. were given together 30 minutes after induction, presumably because of inadequate relaxation. Following these drugs her systolic pressure rose from 90 to $100 \mathrm{~mm}$. $\mathrm{Hg}$, and the pulse rate increased from 100 to 126 beats per minute. No abnormal temperature was recorded on the day of operation, and there was normal recovery from anaesthesia. Pyrexia to $100.4^{\circ} \mathrm{F}$. occurred on the day following operation, but settled rapidly, and she made an uneventful recovery.

\section{Discussion}

\section{Initial Treatment}

The occurrence locally of a case of hyperthermia ${ }^{6}$ had stimulated intense interest in reports of similar cases, especially those associated with abnormal reactions to muscle relaxants. ${ }^{1-4}$ Although the initiating mechanism was obscure, it seemed that all the symptoms and laboratory findings reported could be explained as a natural consequence of sustained muscle hypertonicity, such as is seen to a lesser extent in tetanus infection or status epilepticus. Symptomatic treatment would therefore include measures to reduce hypertonicity as well as measures to correct the hyperthermia and acidosis. Hypertonicity in severe tetanus has been treated with chlorpromazine, or muscle relaxants, ${ }^{6}$ with control of heat production. It had also been noted that in one reported case of hyperthermia where d-tubocurarine was used, ${ }^{1}$ hyperthermia did not appear until the curare effect had dissipated. Thus, when chlorpromazine and diazepam proved ineffective in reducing the muscle spasm encountered here, d-tubocurarine was given, and adequate doses appeared to be effective.

A high serum potassium was reported by Thut and Davenport, ${ }^{2}$ and it is known that in normal individuals a far greater rise in serum potassium occurs following the administration of succinylcholine than following acetylcholine, presumably due to widespread simultaneous depolarization. In view of the deleterious effects of high potassium levels on the heart, and of the counterbalancing of this effect to some extent by ionized calcium, it was felt that calcium should be tried in any hyperthermic or hypertonic state. The marked carpopedal spasm typical of low 
serum calcium tetany seen in this patient and others ${ }^{2,3}$ also encouraged the use of calcium, although all serum calcium reports from all cases have been within normal limits. Since this patient responded directly and dramatically to calcium gluconate intravenously, it is concluded that this therapy, although empiric, is beneficial in hyperthermia. The occurrence of a severe metabolic acidosis is to be expected in hyperthermia and has been noted in several reports, ${ }^{1,8}$ hence large quantities of sodium bicarbonate were given empirically before any determination of acid-base balance or serum electrolytes. Thus the actual levels of $\mathrm{pH}$ and serum potassium present before treatment must have been more abnormal than actually determined on the first specimens.

There is a distinct impression from the above case reports that the situation remains controlled so long as the patient remains anaesthetized, and that rapid deterioration only occurs when anaesthesia is lightened on withdrawal of the anaesthetic, or shortly afterwards. Anaesthesia, of course, abolishes shivering in the induction of hypothermia, and some of us (I.E.P., R.A.P.F.) have used deep anaesthesia to prevent death from hyperpyrexia in status epilepticus. If anaesthesia does delay the onset of hyperthermia, this may well account for the varying time interval between the succinylcholine "trigger" and the hyperthermia response noted in these reports. The fact that hyperthermia can occur without an abnormal reaction to succinylcholine may mean that more than one aetiological factor may be responsible for this syndrome. If a temperature rise is noted under anaesthesia, following an abnormal reaction to succinylcholine, and before the patient's condition has deteriorated, the maintenance of adequate anaesthesia with or without the use of d-tubocurarine may delay the onset of severe hyperthermia and allow effective active cooling to be undertaken before the patient reaches the stage of rapid deterioration.

\section{Changes in Bload Coagulation}

In this patient there was a reduction in blood clotting factors II, V, VII, X, XI and thrombocytopenia. Mild fibrinolysis was also present as demonstrated by the slight reduction of euglobulin lysis time. The low factor II, and thrombocytopenia with only minimal fibrinolysis, suggested that disseminated intravascular coagulation was responsible for the reduction of clotting factors and the haemorrhagic disorder. ${ }^{7}$ As a consequence secondary fibrinolysis could have been initiated although tissue activators could have induced mild primary fibrinolysis.

Control of bleeding could not be achieved with either heparin or epsilonamino caproic acid, although initially the results with the former were encouraging. It is also worth noting that infusion of fibrinogen and fresh frozen plasma seemed to have no deleterious effect in this patient. When the wound was reexplored after failure of medical therapy to control bleeding, some arterial bleeding was evident, although generalized oozing occurring from the entire area presented the major problem. The bleeding was finally controlled by extensive cauterization of these small oozing points. In retrospect, one wonders whether the hyperventilation, the cyanosis of peripheral blood and decreased bleeding noted early in the course of this anaesthetic could be explained on the basis of coagulation occurring in capillaries in the systemic and pulmonary circulation, 
with the development of shunting and a lowered arterial $\mathbf{P}_{\mathbf{O}_{2}}$. It is intended to examine this possibility in any further cases of abnormal reactions to succinylcholine since it might indicate that a change in the coagulating mechanism may be a necessary precursor to hyperthermia. The possibility of a mismatched transfusion being the cause of this coagulopathy was not ruled out by a re-examination of residues of blood administered, but it is felt that the fact that onset of symptoms preceded the giving of blood renders this possibility unlikely. This continued consumption of coagulation factors led to a marked coagulation defect in the following hours, and it may be significant that a return of increased coagulability of blood was noted in the last ante mortem specimen taken for electrolytes, at a time when the temperature was near normal, but when serum potassium was increased. This change preceded the recurrence of tetany by about 35 minutes.

It is of interest that Cullen's second case $^{3}$ showed profuse bleeding into the gastrointestinal tract, and that the urine was positive for haemoglobin, suggesting that this patient also had a coagulation defect associated with hyperthermia.

\section{Familial Link}

Anaesthetic deaths of ten members of one family were reported by Denborough et al., and hyperthermia was associated with at least two of these deaths. Although muscle relaxants were not used, halogenated agents were employed in all the decedents, who received ethyl chloride with ether. Halothane was used for another member who exhibited a severe reaction, possibly associated with hyperthermia, followed by recovery. This is the first occasion on which two related members of a family have been reported to exhibit an abnormal reaction to succinylcholine followed by hyperthermia and death. In view of the relatively large numbers of cases being reported from centres in Canada, it is possible that this reaction may occur more frequently in families with French-Canadian ancestors.

\section{Possible Mechanisms}

A genetically determined abnormality of the myoneural junction might be postulated to cause persistence of succinylcholine at the end plate region, with repetitive depolarization and repolarization, giving rise to continued loss of muscle cell constituents, including cellular potassium and substances capable of inducing blood coagulation. Following initiation of intravascular clotting in the microvasculature, peripheral slowing of the circulation, shunting, and hyperventilation could occur. An alternative hypothesis to explain the decreased levels of clotting factors could be that the hypotension resulted in slowing of the circulation in the microvasculature and in the presence of acidosis disseminated intravascular coagulation occurred.9 Eventually the clotting factors would be consumed faster than they could be produced, and a clotting defect would emerge. ${ }^{7}$ According to the former hypothesis, d-tubocurarine would block the cycle of repetitive depolarization. Low molecular weight dextran and heparin given early might counteract the effects of coagulation, and the administration of intravenous fluids and diuretics to dilute and flush out the intravascular potassium would be indicated, together with calcium ions to counteract the effect of potassium on the heart. 
Eventual destruction of succinylcholine by hydrolysis could be expected, but could be hastened by the administration of normal pseudocholinesterase, unless the succinylcholine is bound in such a way that it is no longer susceptible to enzymatic attack. It is possible that halogenated anaesthetics might act through delaying the breakdown of this abnormally bonded succinylcholine, or might favour the development of coagulation, thus hindering the removal of succinylcholine from the end plate region. A third mechanism in which halogenated anaesthetics may enhance the effect of succinylcholine is through release of potassium from cell mitochondria, ${ }^{10}$ this potassium then being lost to the cell through the effect of succinylcholine on the cell membrane.

\section{SUMMARY}

A death from hyperthermia following an abnormal reaction to succinylcholine is reported, and it is noted that a similar death occurred in a close relative. D-tubocurarine produced relaxation of severe muscle spasm associated with this hyperthermia, and relaxation remained when the patient was cooled into hypothermia but the hypertonicity recurred as a terminal event. Raised serum potassium levels were associated with the hypertonus, and the intervening hypotonic phase was associated with lowered serum potassium levels. Although serum calcium levels remained normal, intravenous calcium gluconate improved the circulatory state of the patient. A consumption coagulopathy was noted during the hypotonic phase, and increased coagulability was noted during the hypertonic phases. Treatment and possible mechanisms of action of succinylcholine in the production of hyperthermia are discussed.

\section{Résumét}

Nous avons rapporté un cas de mort par hyperthermie à la suite d'une réaction anormale à la succinylcholine et nous avons noté qu'un proche parent de notre patient est mort dans des conditions identiques. La d-tubocuraraine a produit un relâchement du spasme musculaire sévère associé à cette hyperthermie et le relâchement a persisté quand le patient fut refroidi hypothermie, mais on a noté de nouveau l'hypertonicité au stage terminal. Une élévation du potassium sérique fut associé à l'hyptertonie, tandis que la phase hypotonique fut associée à un potassium sérique abaissé. Bien que le calcium sérique soit demeuré normal, le gluconate de calcium par voie veineuse améliora l'état circulatoire du patient.

Pendant la phase hypotonique, on nota une coagulopathie, mais la coagulabilité fut augmentée pendant la phase hypertonique. Nous avons discuté du traitement et des mécanismes d'action possibles de la succinylcholine dans la production d'hyperthermie.

\section{REFERENCES}

1. Rerton, J. E. S.; Creighron, R. E.; Johnston, A. E.; Pelton, D. A.; \& Conn, A. W. Hyperpyrexia in Association with General Anaesthesia in Children. Canad. Anaesth. Soc. J. 13: 419 (1968). 
2. Thut, W. H. \& Daventort, H. T. Hyperpyrexia Associated with SuccinylcholineInduced Muscle Rigidity: A Case Report. Canad. Anaesth. Soc. J. 13: 425 (1966).

3. Culluen, W. G. Malignant Hyperpyrexia during General Anaesthesia: A report of Two Cases. Canad. Anaesth. Soc. J. 13: 437 (1966).

4. LavoIE, G. Hyperpyrexia during General Anaesthesia: A Case Report. Canad. Anaesth. Soc. J. 13: 444 (1966).

5. ANDERson, T. A. Personal communication: material to be published.

6. Purkss, I. E. \& CurTrs, J. E. The Management of Severe Tetanus. Canad. M.A.J. 93: 1200 (1965).

7. Rodrupuez-Erdman, F. Bleeding Due to Increased Intravascular Blood Coagulation. New England J. Med. 273: 1370 (1965).

8. Denborough, M. A.; Forster, J. E.; Lovell, R. R. H.; Mapleston, P. A.; \& Villiers, J. D. Anaesthetic Deaths in a Family. Brit. J. Anaesth. 34: 395 (1962).

9. HARDawax, R. M. Intravascular Coagulation in Irreversible Shock. Shock and Hypotension. L. C. Mills and J. H. Moyer, eds. New York: Greene and Stratton (1965).

10. Snodgrass, P. J. \& Pras, M. M. The Effects of Halothane on Rat Liver Mitochondria. Biochemistry. 5: 1140 (1966). 